\title{
Tensile Behaviour of Oil Bean Pod Shell and Mahogany Sawdust Reinforced Epoxy Resin Composite
}

\author{
Umurhurhu Benjamin ${ }^{1}$, Uguru Hilary ${ }^{2, *}$ \\ ${ }^{1}$ Department of Mechanical Engineering Technology, Delta State Polytechnic, Ozoro, Nigeria \\ ${ }^{2}$ Department of Agricultural and Bio-environmental Engineering Technology, Delta State Polytechnic, Ozoro, Nigeria
}

Email address:

erobo2011@gmail.com (U. Hilary)

${ }^{*}$ Corresponding author

\section{To cite this article:}

Umurhurhu Benjamin, Uguru Hilary. Tensile Behaviour of Oil Bean Pod Shell and Mahogany Sawdust Reinforced Epoxy Resin Composite. International Journal of Science, Technology and Society. Vol. 7, No. 1, 2019, pp. 1-7. doi: 10.11648/j.jjsts.20190701.11

Received: December 8, 2018; Accepted: January 5, 2019; Published: February 25, 2018

\begin{abstract}
The influence of fillers loading rate on the tensile behaviours (tensile strength, Young Modulus, tensile energy, tensile strain and Stress at LOP) of reinforced epoxy composites were investigated in this research. Both filler materials (OBPS and SD) where treated with $5(\mathrm{w} / \mathrm{v}) \%$ Sodium hydroxide solution for 1 hour at ambient temperature of $27 \pm 3^{\circ} \mathrm{C}$. The composite samples were prepared with five different volume (10, 15, 20, 25 and 30 vol\%) of OBPS and SD in the ratio of 1:1, using the hand lay-up method. All the composite samples were prepared and tested according to ASTM standards, using the Universal Testing Machine. Results from this present research showed that the fillers loading had significant $(\mathrm{P} \leq 0.05)$ effect on all the tensile behaviors investigated. In addition, the results showed that all the five tensile behaviours of the samples increased gradually with increase in fillers loading. The tensile strain increased by $53.18 \%$, as the fillers loading increased from $10 \%$ to 30 vol.\%.in addition the tensile strength increased from 7.86 to $27.47 \mathrm{MPa}$, while the Young modulus increased from 668.4 to 1235.93 MPa. Results obtained from this study can be helpful in the production of composite boards for industrial applications.
\end{abstract}

Keywords: Mahogany, Sawdust, Tensile Properties, Oil Bean Shell, Epoxy Composite

\section{Introduction}

Nigeria forests contain large varieties of plants with different fibre content. Mahogany tree (Swietenia mahagnoni) is a straight-grained, reddish-brown hardwood. Mahogany resists wood rot, making it attractive in boat construction and outdoor decking [1]. Mahogany is also used in musical instruments, mostly the wooden parts of acoustic and electric guitars. In addition, it is used in drum shells because of its ability to produce a very deep, warm tone, when compared to other woods, such as maple or birch [2-3]. In addition, mahogany seed contains so many health benefits that it is very sought after in some countries. Studies have established that mahogany seed contributes greatly in lowering cholesterol. This could be attributed to the reasonable amount of flavonoid contained in the seed, which can help in blood circulation. Furthermore, mahogany is rich in saponins, which help in preventing blood clotting and enhancing better heart condition [4].
Composite materials composed of two or more components combined in a ratio that allows the new materials to be distinct and identifiable. The initial components add strength and other tensile behaviours to a composite, therefore, the product often compensates for the weaknesses of each individual components. The tensile properties of composites are strongly dependent on the properties, distribution and the interaction among the constituent materials. The composite properties may be the volume fraction sum of the properties of the constituents or the constituents may interact in a synergistic way, thereby resulting in more improved properties [5-6]. Over the years, applications of composites materials have increased tremendously. The use of composites depend on many factors such as; working, lifetime requirements, complexity of product shape, costs savings, and on the experience and skills the designer in tapping the optimum potential of composites [5].

Composite materials are classified by the type of reinforcement used with the matrix. The reinforcement is incorporated into a matrix which holds it together. The reinforcement is used to strengthen the composite products. 
For instance, in a resin composite board, the matrix is the resin and the reinforcement can be corn husk, sawdust, fiberglass, straw etc. Common composite types include random-fiber or short-fiber reinforcement, continuous-fiber or long-fiber reinforcement, particulates reinforcement, flake reinforcement, and fillers reinforcement [6]. Natural materials reinforced composites have been increasingly used in widespread engineering and textile applications. For instance, jute, flax and sisal fibres are used nowadays in automotive industry [7]. The applications of natural fibres in composites depend on their composition, physical and mechanical properties [8]. Limitations of natural fibres applications in industrial practice can be attributed to their relatively high hydrophilic behaviours. This affects the interfacial adhesion between the fibres and the polymer matrix, hence reducing the mechanical properties of their composites [9]. Some advantages of natural fibres over synthesized fibres are their low density, high toughness, comparable specific strength properties, ease of separation and moulding, environmental friendliness, low cost and improved stiffness $[8,10,11]$.

Many researchers have investigated the tensile properties of various natural fibres composites. Aji et al [12] studied the mechanical properties of kenaf/PALF fibres reinforced polyethylene composites. Their results showed that fibres loading ratios and finres length had effect on the storage modulus of the hybrid composites. Furthermore, Taib [13] reported in their study that the impact strength and elongation at break of ethylene acrylate-modified kenaf fibre reinforced polylactic acid composites were improved by increasing the modifier content but an opposite trend was observed for the tensile strength and modulus. The effects of alkaline treatment on the mechanical properties of bagasse fibre reinforced composites were investigated by [14]. Their results showed that the mechanical properties of the composites made from the treated fibres were better than the untreated fibres. They reported approximately $13 \%$ improvement in tensile strength, $14 \%$ in flexural strength and 30\% in impact strength had been found, respectively. Furthermore, John [15] studied the potential of carbonized bagasse (waste from sugar cane) as fillers in composites. They reported that as the filler loading increased the tensile strength, abrasion resistance, and hardness properties improved. In addition, they observed that decreased in the fillers loading enhanced the elongation at break and compression set properties. In addition, [16] studied the tensile strength and modulus of chemically extracted elephant grass fibre composites. They reported that the above mentioned mechanical properties increased approximately 1.45 times to those of elephant grass fibre composite extracted by retting.

Even though, much work have been done on natural materials composites, research works on the oil bean pod shell (OPBS) and mahogany sawdust (SD) composites are scanty. Therefore, the objective of this research was to study and evaluate the tensile properties of OBPS and SD reinforced epoxy composites, to establish its usefulness in industrial applications.

\section{Materials and Methods}

\subsection{Samples Collection and Preparation}

The oil bean pod shells used for this research were picked from environment of the Delta State Polytechnic, Ozoro, Nigeria. The collected shells were ground using a burr mill, to reduce them to particulates size, which was later treated with $5 \% \mathrm{NaOH}$ for 1 hour to enhance their tensile properties. Lastly, the particulates were sieved with $150 \mu$ stainless steel sieve.

Mahogany timber was obtained from local timbers dealer in Oleh, Delta State, Nigeria. In order to obtain sawdust from the timber; it was sawed with fine teeth saw blade. The saw dust obtained was treated with $5 \% \mathrm{NaOH}$ solution for 1 hour at ambient temperature of $27 \pm 3^{\circ} \mathrm{C}$, dried in laboratory oven at $100^{\circ} \mathrm{C}$ for 8 hours, and sieved through with a $300 \mu$ stainless sieve. The Epoxy resin and hardener used for this research were purchased from an industrial chemical shop located at Onistha in Anambra State, Nigeria.

\subsection{Composite Preparation}

The composite samples were prepared by hand lay-up technique. A wooden mould of dimension $200 \times 150 \times 5$ $\mathrm{mm}^{3}$ (based on ASTM standard) was used for the casting. A thin wax film was first applied to the mould, to facilitate the release of the composite from the mould. The composite samples were made with fillers (Oil bean pod shell and saw dust) loadings of $10 \%, 15 \%, 20 \%, 25 \%$ and $30 \%$, in the ratio of $1: 1$. The epoxy and hardener were mixed in the ratio of $4: 1$ to produce the matrix. During the casting, measured quantities of OBPS, SD and the resin were poured into a plastic bucket and stirred thoroughly for 30 minutes to obtain a homogeneous mixture. After that, the right quantity of the hardener was added to the mixture in the plastic bucket and again stirred carefully again for 10 minutes; before the mixture was poured into the already prepared mould. The casted composite was kept under a dead load of $20 \mathrm{~kg}$ at ambient temperature for 24 hours to expel any entrapped air from it; after which, it was stripped off from the mould and cured at room temperature for 21 days [10]. Finally, after the curing, the composite board was cut into the tensile samples shape based on ASTM D638 standard.

\subsection{Tensile Testing}

The tensile strength of the composite samples was measured at the material testing laboratory of National Centre of Agricultural Mechanization, Ilorin, Kwara State, Nigeria. The samples were tested with the Universal Testing Machine (UTM) (Testometric model), in accordance with the ASTM D638 procedure. Ten replicas were done on each composite sample and the average values of tensile behaviours (tensile strength, Young Modulus, tensile energy, tensile strain and Stress at LOP) were recorded.

\subsection{Statistical Analysis}

Data obtained from this present study were subjected to 
Analysis of variance using SPSS statistical software (version 20.0, SPSS Inc, Chicago, IL). In addition, the mean values of the parameters were separated using Duncan's multiple range tests at $95 \%$ confidence level.

\section{Results and Discussion}

The Analysis of Variance (ANOVA) results of the effect of fillers loading on the tensile properties of epoxy composites are presented in Table 1. From Table 1, it can be seen that the fillers loading had significant $(\mathrm{P} \leq 0.05)$ effect on all five tensile behaviours investigated in this research. Summary of the regression equations are shown on the regression in Table 2 . The high correlation values $(\mathrm{r} \geq 0.90)$ in Table 2 showed that strong relationship existed between the fillers loading and the various tensile behaviours.

Table 1. ANOVA for response of tensile behaviour of Epoxy/OBPS/SD composite to fillers loading.

\begin{tabular}{llll}
\hline Source of variation & Dependent variable & df & Sig \\
\hline & Tensile strength & 4 & $2.69 \mathrm{E}-11^{*}$ \\
& Young modulus & 4 & $4.84 \mathrm{E}-08^{*}$ \\
$\mathrm{~L}$ & Stress at LOP & $4.97 \mathrm{E}-09^{*}$ & $3.19 \mathrm{E}-08^{*}$ \\
& Tensile energy & 4 & $4.38 \mathrm{E}-10^{*}$ \\
\hline
\end{tabular}

$\mathrm{L}=$ filler loading rate; $*=$ Significant at $(\mathrm{P} \leq 0.05) ; \mathrm{df}=$ degree of freedom.

Table 2. Regression equations of the effect of fillers loading on the tensile behaviour of Epoxy/OBPS/SD composite.

\begin{tabular}{llllll}
\hline Parameter & Linear equation & $\mathbf{R}^{2}$ & Power equation & $\mathbf{R}^{2}$ & r \\
\hline Tensile strength & $\mathrm{y}=5.332 \mathrm{x}+2.204$ & 0.971 & $\mathrm{y}=10.31 \mathrm{x}^{0.74}$ & 0.946 & 0.987 \\
Young Modulus & $\mathrm{y}=143.5 \mathrm{x}+507.8$ & 0.992 & $\mathrm{y}=638.6 \mathrm{x}^{0.383}$ & 0.956 & 0.996 \\
Tensile energy & $\mathrm{y}=1.346 \mathrm{x}+5.404$ & 0.989 & $\mathrm{y}=6.539 \mathrm{x}^{0.361}$ & 0.969 & 0.966 \\
Stress at LOP & $\mathrm{y}=1.592 \mathrm{x}+3.578$ & 0.964 & $\mathrm{y}=4.963 \mathrm{x}^{0.501}$ & 0.994 \\
Tensile strain & $\mathrm{y}=1.151 \mathrm{x}+2.33$ & 0.975 & $\mathrm{y}=3.443 \mathrm{x}^{0.497}$ & 0.923 \\
\hline
\end{tabular}

Where $\mathrm{y}=$ the parameter, $\mathrm{x}=$ composite sample, $\mathrm{R}^{2}=$ coefficient of determination, $\mathrm{r}=$ correlation.

The results of the effect of fillers loading the tensile behaviours of composites samples, obtained from this study are presented in Figures 1 to 5. From the results, it was clear that the fillers application improved the tensile properties of the composites samples. Figure 1 showed the effect of fillers (OBPS and SD) loading on the tensile strength of the composite board. From the Figure 1, it can be clearly seen that the tensile strength of the composite board increased with increase in the fillers loading. The maximum tensile strength of $27.47 \mathrm{MPa}$ was recorded at $30 \%$ volume fillers ratio. As shown in Figure 1, no significant difference ( $P$ $\leq 0.05)$ was observed between the tensile strength of composite samples 4 and 5. In addition, from the results, the Young modulus increased by $45.92 \%$ with the addition of the fillers. The tensile strain of the OBPS and SD reinforced composite specimens are presented in Figure 5. As shown in the plot (Figure 5), the tensile strain was increased by $11.13 \%, 34.55 \%, 47.98 \%$ and $53.18 \%$ for the samples S2, S3, S4 and S5 respectively as compared to the sample S1. In addition, from the plot in Figure 5, no significant difference $(\mathrm{P} \leq 0.05)$ was observed in the tensile strain between samples 1 and 2. Similar result was obtained for Iroko timber sawdust and oil bean pod shell reinforced epoxy composites, where tensile strength increased up to $50 \%$ fillers loading before it started decreasing [10].

Furthermore, from previous study, the specific tensile strength of banana, sisal and okra fibres composites increased with increasing volume fraction of fibre linearly up to the volume fraction of $20.4 \%$ [17]; additionally, the tensile strength of bagasse fibre composites increased from 16.5 to 23.5 $\mathrm{MPa}$, as the fibre content increased from 20 to 65(wt \%) [14]. Motaleb studied the influence of alkaline treatment on mechanical properties of pineapple and jute fabric reinforced polyester resin composites. He observed the tensile strength of the composites reinforced with alkaline treated fabric increased by approximately $30 \%$ when compared to the pomposities reinforced with untreated fabric [18]. In the study of Kalam [19], the tensile strength for OPFBF/epoxy composites at $35 \mathrm{vol} \%$ was $47.8 \mathrm{MPa}$ and for OPFBF/epoxy composites at $55 \mathrm{vol} \%$ was $46.1 \mathrm{MPa}$. Furthermore, another research stated that tensile properties of short-fibrereinforced composites strongly depend on fibre length, fibre volume fraction, fibre dispersion, fibre orientation and fibre /matrix interfacial strength [20]. A similar trend was reported for short pineapple leaf fibre (PALF) treated with $2 \% \mathrm{NaOH}$ improved the tensile strength and tensile modulus of the composites board by $12 \%$ and $31 \%$, respectively, compared with the untreated fibre composites [21]. The better tensile strength results obtained from the alkaline-treated reinforcement materials could be attributed to the improved adhesive characteristics of fibre/filler surfaces. This is caused by the removal of the natural and other impurities from the reinforcement materials, thereby producing a rough surface topography. In addition, alkaline treatment leads to fibre fibrillation, i.e. breaking down of the fibre bundles into smaller fibres. This increased the effective surface area of the fibre and the matrix [21-22]. 


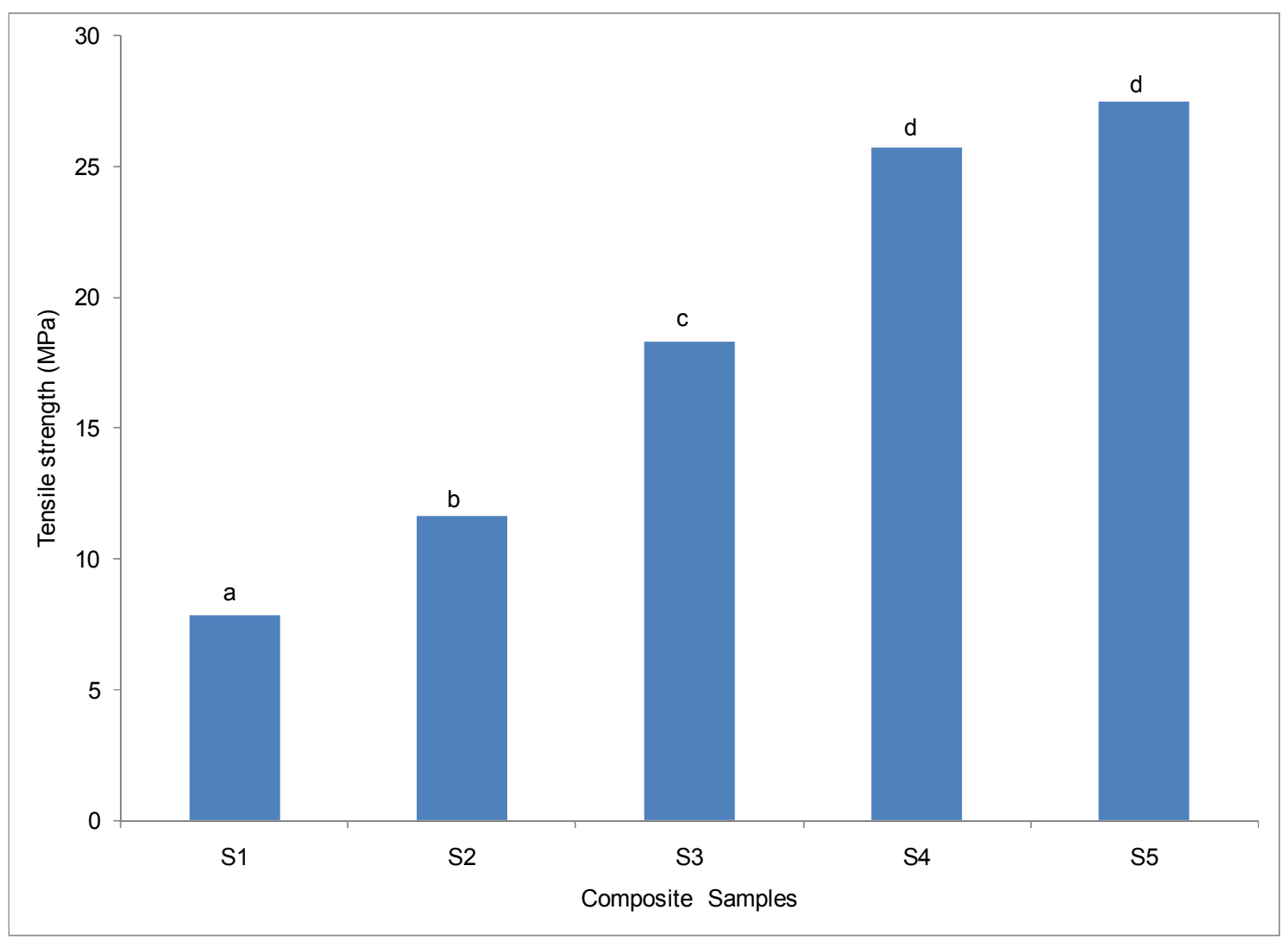

Bars with the same common letters means that they are not significant different at $(\mathrm{P} \leq 0.05)$.

Figure 1. Effect of fillers loading on the tensile strength of composite samples.

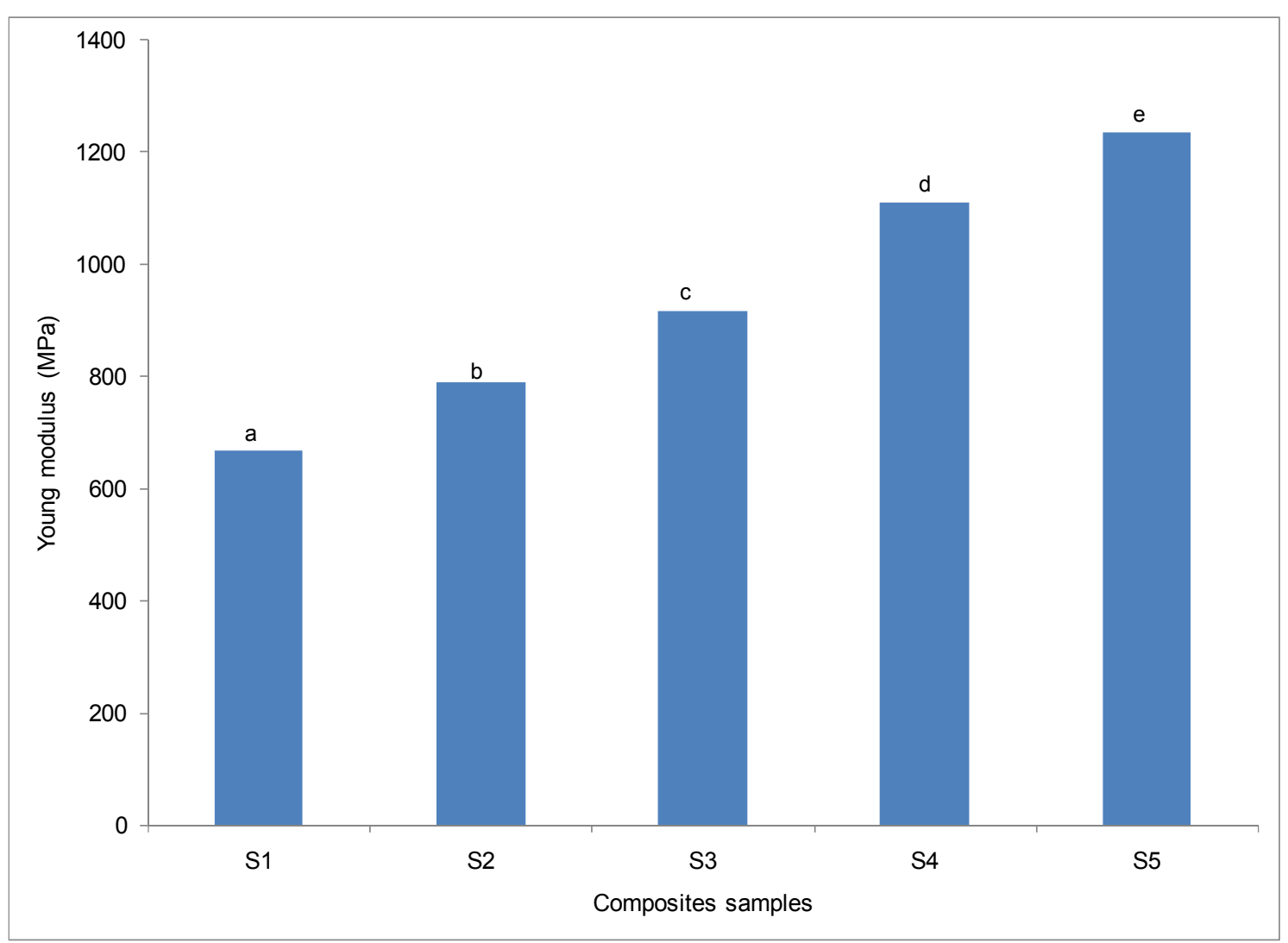

Bars with the same common letters means that they are not significant different at $(\mathrm{P} \leq 0.05)$.

Figure 2. Effect of fillers loading on the Young modulus of composite samples. 


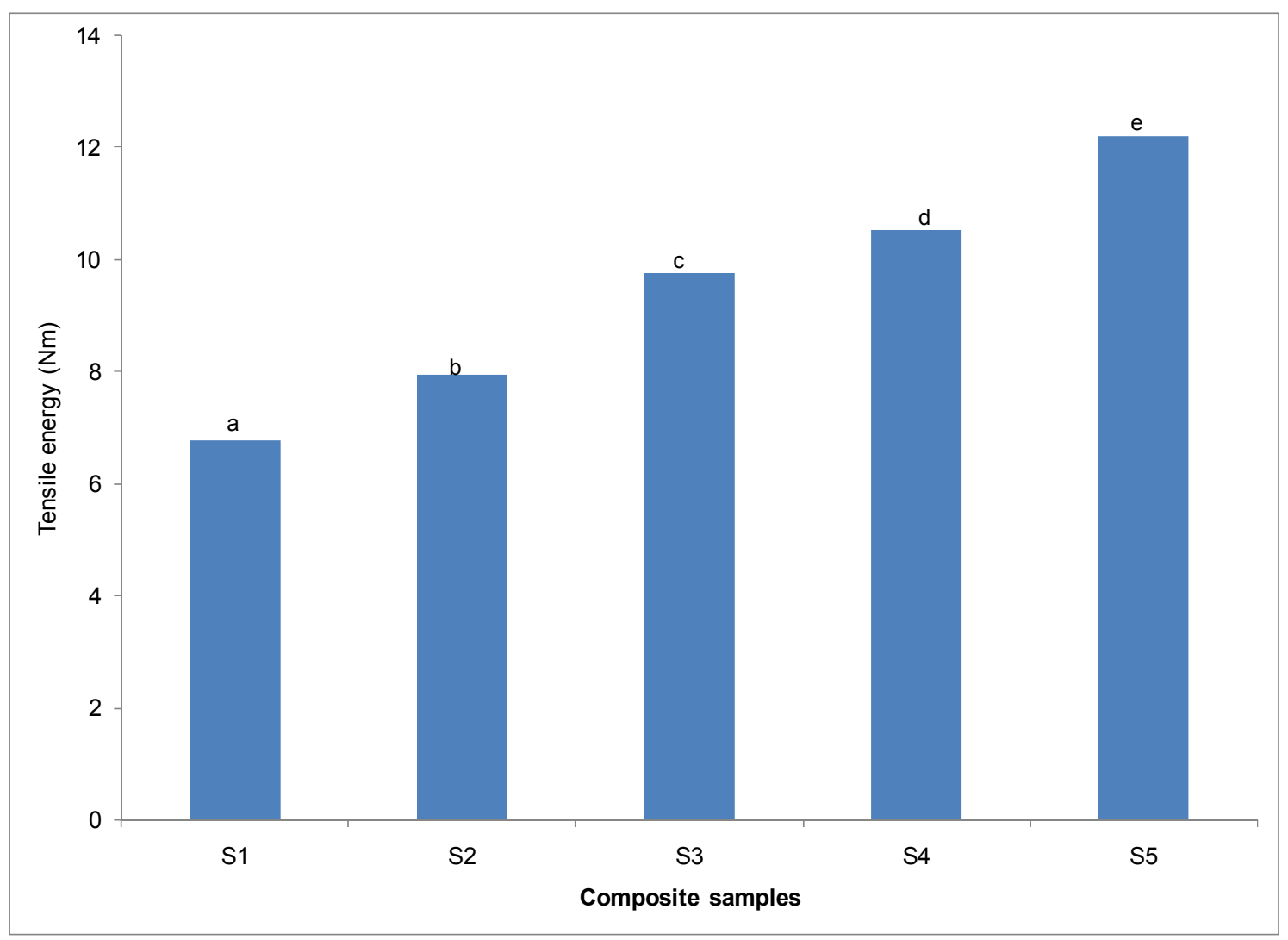

Bars with the same common letters means that they are not significant different at $(\mathrm{P} \leq 0.05)$.

Figure 3. Effect of fillers loading on the tensile energy of composite samples.

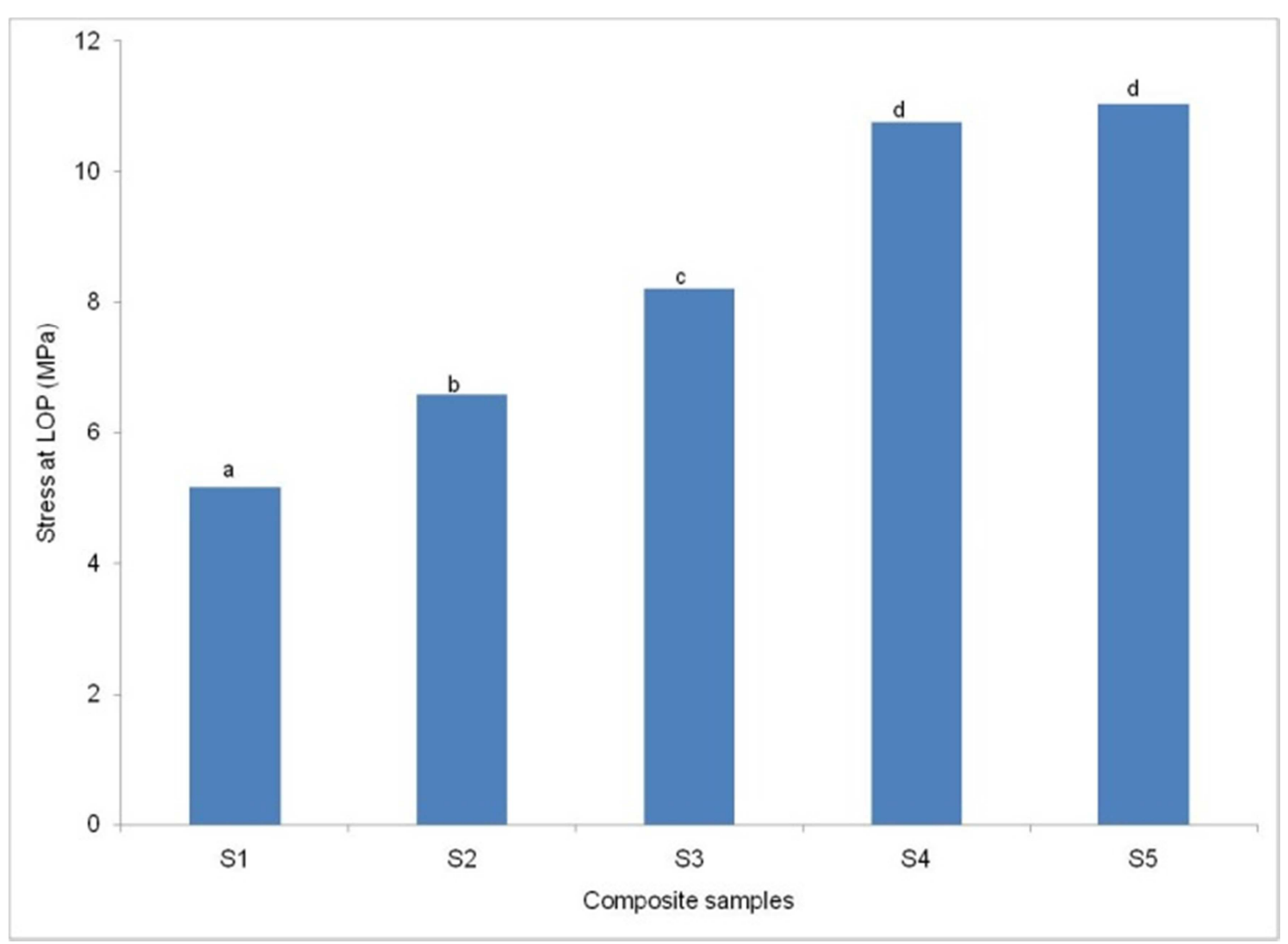

Bars with the same common letters means that they are not significant different at $(\mathrm{P} \leq 0.05)$.

Figure 4. Effect of fillers loading on the stress at LOP of composite samples. 


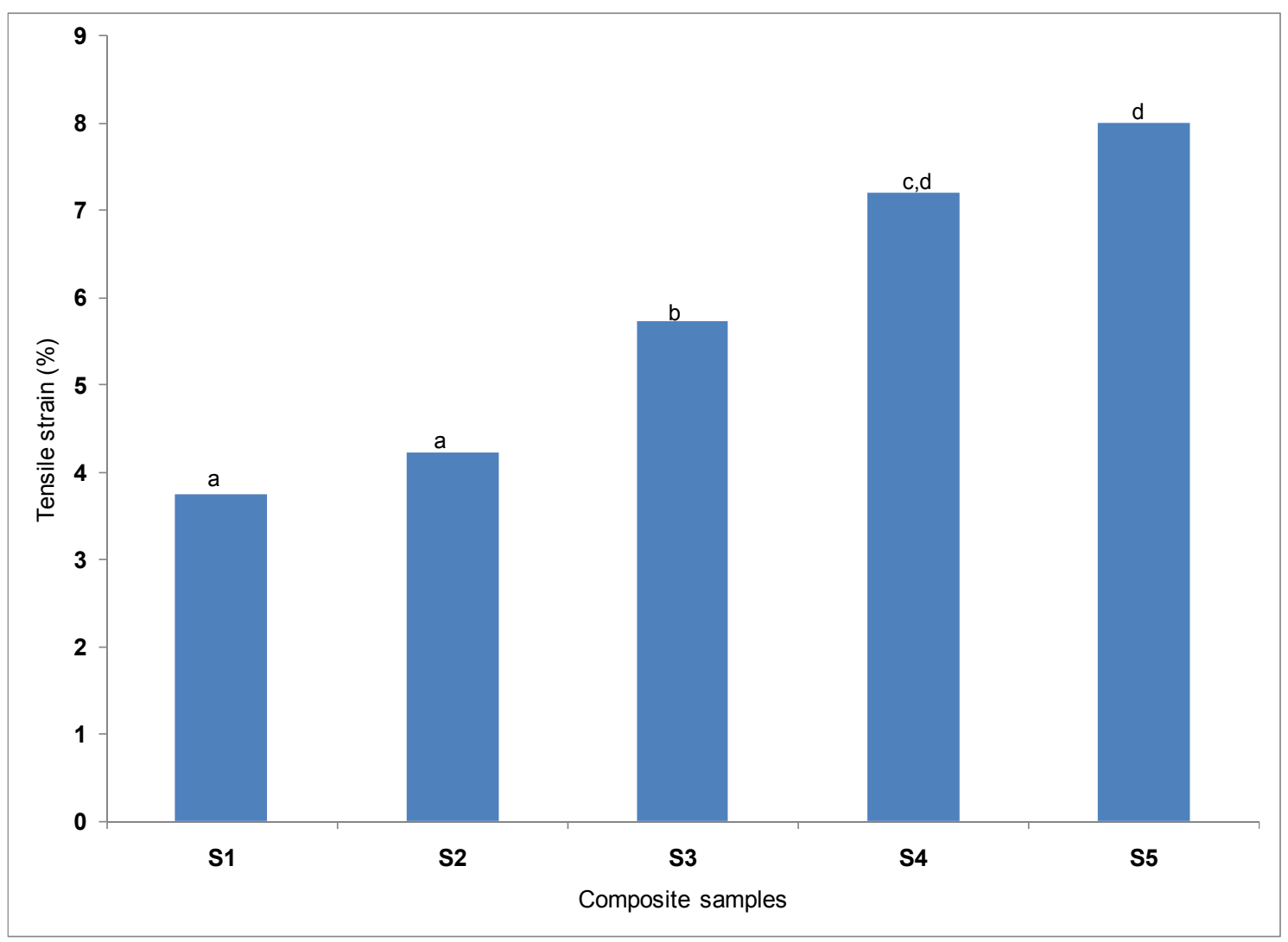

Bars with the same common letters means that they are not significant different at $(\mathrm{P} \leq 0.05)$.

Figure 5. Effect of fillers loading on the tensile strain of composite samples.

\section{Conclusions}

In this study, the tensile behaviours of OBPS and SD reinforced epoxy composite samples were investigated. The results obtained in this research also showed that fillers loading rate affects the mechanical properties of the composite materials. From the results obtained, it was found that the tensile behaviours showed an increasing trend as the fillers rate increased up $30 \%$ volume. The tensile strength showed remarkably increment with the fillers loading. Young modulus of the composite samples was increased by $45.92 \%$, while the tensile strain was increased by $53.18 \%$. Data gotten from this present research can be useful in the production of composite boards for engineering applications.

\section{References}

[1] Samuel, B (2012). A Natural History of Belize: Inside the Maya Forest. Austin: University of Texas Press. 164-165.

[2] Bruck, M, (2005). Guitar World Presents Guitar Gear 411. Alfred Music Publishing.

[3] Hirst, T. (2003). Electric Guitar Construction. Hal Leonard Corporation.

[4] Skyfruitseed (2018). "Mahogany". Available at: https://skyfruitseed.com/important-facts-and-informationabout-mahogany/.
[5] Verma, D., Gope, P. C., Maheshwari, M. K. and Sharma, R. K. (2012). Bagasse fiber composites-A Review. J. Mater. Environ. Sci. 3 (6): 1079-1092.

[6] Kennedy, D. (2018). Types of composite materials. Available at: https://sciencing.com/types-composite-materials-5868282.html.

[7] Jacob, M., Thomas, S. and Varughea, K. T. (2004). Mechanical properties of sisal/oil palm hybrid fibre reinforced natural rubber. Composites Science and Technology, 64(7-8): 955-965.

[8] Brígida, A. I. S., Calado, V. M. A., Gonçalves, L. R. B. and Coelho, M A Z. (2010). Effect of chemical treatments on properties of green coconut fiber. Carbohydr. Polym., 79(4): 832-838.

[9] [9] Mokaloba, N. and Batane, R. (2014). The effects of mercerization and acetylation treatments on the properties of sisal fiber and its interfacial adhesion characteristics on polypropylene. Int J Eng. Sci. Technol. 6(4): 83-97.

[10] Prosper. O and Uguru, H. (2018). Effect of fillers loading on the mechanical properties of hardwood sawdust/oil bean shell reinforced epoxy hybrid composites. Int J S Res Sci. Engg. Tech. 4(8): 620-626.

[11] Wang, B., Panigrahi, S., Tabil, L., Crerar, W., Sokansanj, S and Braun, L. (2003). Modification of flax fibers by chemical treatment. CSAE/SCGR 2003 Meeting Montréal, paper no. 03-337, Québec: 1 - 15.

[12] Aji I S, Zainudin E S, Sapuan S M, Khalina A and Khairul M D (2012), Study of hybridized kenaf/PALF-reinforced hdpecomposites by dynamic mechanical analysis. Polym.Plast. Technol. Eng. 51(2):146-153. 
[13] Taib R M, Hassan H M and Ishak Z A. M (2014). Mechanical and morphological properties of polylactic acid/kenaf bast fiber composites toughened with an impact modifier. Polym. Plast. Technol. Eng. 53(2): 199-206.

[14] Cao, Y., Shibata, S. and Fokumoto, I. (2006). Mechanical properties of biodegradable composites reinforced with bagasse fiber before and after alkali treatment. Composites Part A, Applied Science and Manufacturing 37: 423-429.

[15] John, O. O. and Samuel, I. A. (2010). Potential of carbonized bagasse filler in rubber products, J. Emer. Trends in Eng. Appl. Sci. (JETEAS) 1:157-160.

[16] Murali M. R. K., Ratna P. A. V., Ranga, B. M., Mohan R. K. and Gupta A. (2007). Tensile properties of elephant grass fiber reinforced polyester composites. J. Mat. Sci. 42: 3266-3272.

[17] Srinivasababu, N., Rao, K. M. and Kumar, J. S. (2009). Experimental determination of tensile properties of okra, sisal and banana fiber reinforced polyester composites. Indian Journal of Science and Technology. 2(7): 35 - 38.

[18] Motaleb, K. S. M. (2018). Improvement of mechanical properties by alkali treatment on pineapple and jute fabric reinforced polyester resin composites. International Journal of Composite Materials. 8(2): 32-37.

[19] Kalam, A., Sahar, B. B., Khalis, Y. A. and Wong, S. V. (2005) Fatigue behaviour of oil palm fruit bunch fibre/epoxy and carbon fibre/epoxy composites. Composite Structure. 71: 3444.

[20] Li, Y., Mai, Y. W. and Ye, L. (2000). Sisal fibre and its composites: a review of recent developments. Composites Science and Technology 60: 2037-2055.

[21] Siregar, J. P., Sapuan, S. M., Rahman, M. Z. A., and Zaman, H. M. D. K. (2010). The effect of alkali treatment on the mechanical properties of short pineapple leaf fibre (PALF) reinforced high impact polystyrene (HIPS) composites. $J$. of Food, Agriculture \& Environment. 8(2):1103-1108.

[22] Mohanty, A. K., Mubarak, A. K. and Hinrichsen, G. (2000). Surface modification of jute and its influence on performance of biodegradable jute-fabric/Biopol composites. Composites Science and Technology 60:1115-1124. 